\title{
Enhancing exterior performance of clear coatings through photostabilization of wooden surfaces. Part 1: Treatment and characterization
}

\author{
Bernard S. W. Dawson, Adya P. Singh, Hank W. Kroese, \\ Michael A. Schwitzer, Suzanne Gallagher, Stephen J. Riddiough, \\ Shuhong Wu
}

(C) The Author(s) 2008

\begin{abstract}
The aim of this work was to produce a less photodegradation-prone substrate for clear coating by partially delignifying the surface cells of Pinus radiata boards to a depth of $2-3 \mathrm{~mm}$ while maintaining the integrity of the wood surface tissues in the delignified zone. To achieve this, several surface oxidative delignification treatments were trialled in the method development process and peracetic acid was chosen as the method for refinement and deployment. The treatment method was optimized to yield a significant degree of delignification compatible with the aim of producing a photostabilized yet intact wooden surface. A preweathering technique was also used as a second delignification method for producing photostabilized boards. Microscopic and chemical techniques were used to characterize the effects of chemical and preweathering treatments, which produced delignified surface envelopes $2-3 \mathrm{~mm}$ and $100 \mu \mathrm{m}$ deep, respectively. Acetyl bromide lignin analyses, infrared spectroscopic analyses, and density changes of $30-\mu \mathrm{m}$-thick sections of peracetic-acid-treated samples, as a function of depth from the wood surface, suggested that a partial delignification had occurred that diminished with depth. Light and transmission electron microscopy provided evidence of delignification at the cellular level. In the
\end{abstract}

B. S. W. Dawson ( $₫)$, A. P. Singh,

H. W. Kroese, M. A. Schwitzer, S. Gallagher

Ensis (A Joint Venture of CSIRO \& Scion),

PB Bag 3020, Rotorua, New Zealand

e-mail: bernard.dawson@ensisjv.com

\section{S. J. Riddiough}

School of Agricultural \& Forest Sciences,

University of Wales, Bangor, Wales, UK

$\mathrm{S} . \mathrm{Wu}$

Research Institute of Wood Industry,

Chinese Academy of Forestry, Wan Shou Shan,

Beijing 100091-25, China surface layers of peracetic-acid-treated boards, all cell wall regions were delignified, with the middle lamella being the most severely affected. Lignin appeared to be completely removed from the cell corner middle lamella regions, but tracheids were still joined in other parts of the middle lamella. The $S_{1}, S_{2}$, and $S_{3}$ walls were also delignified. In subsurface layers, cell walls were only partially delignified and the tissues held their integrity. In contrast, in the preweathered boards, cell walls in the outermost layers were completely separated at the middle lamella from photodegradation. Preferential lignin removal over that of hemicelluloses was achieved via oxidative treatment of solid wood. The outcome of this was the successful fulfillment of our aim to produce partially delignified wooden surfaces that retained sufficient strength and aesthetic appearance and were suitable for application in wooden structures, provided that the necessary protection measures were carried out. Due to the narrow surface zone produced, machining of such surfaces would not be recommended as the most delignified zone would be removed first. In Part 2 of this series, the photostability of treated boards, which had been clear coated and weathered, will be considered.

Keywords Peracetic acid treatment, Delignification, Photostabilization, Preweathering treatment, Pinus radiata

\section{Introduction}

Wood degrades due to weathering from the combined effects of solar irradiation and water. ${ }^{1-9}$ Photodegradation of wood and the different ways to stabilize it have been reviewed. ${ }^{9,10}$ Surface photostabilization can significantly extend the service life of clear-coated wooden products placed in outdoor situations. ${ }^{7,11,12}$ The rationale to achieve a photostabilized surface in 
our work was based on the knowledge that wood is a composite consisting of cellulose, lignin, and hemicellulose and that partial removal of lignin from the surface region is likely to render this region less susceptible to photodegradation.

Photodegradation occurs through various pathways where chromophores in the wood surface absorb ultraviolet and visible radiations to create excited molecules. Such molecules participate in different pathways yielding various types of phenoxy radicals, which lead to chain cleavage or colored quinonoid molecules. ${ }^{9}$ Because of the greater relative specific absorption coefficient for lignin compared to cellulose, lignin is a much better absorber of light and is therefore degraded faster than cellulose. The resulting lower-molecular-weight fragments are soluble in rainwater. During weathering-induced photodegradation, loss of lignin from the lignin-rich middle lamella results in surface fibers being liberated from the wood surface. ${ }^{13,14}$ Pigmented coatings have been typically used to prevent such reactions, as solar irradiation is absorbed, scattered, or reflected by the coating and does not reach the wood surface. However, visible and UV radiation inevitably impacts the wooden surface when transparent varnishes are employed, even in the presence of various UV absorbers or free-radical scavengers in such coatings. Therefore, it is important to photostabilize wooden surfaces prior to the application of transparent coatings to increase the exterior performance of clear coatings. This was the concept underlying our attempt to enhance exterior performance of clear coatings through photostabilization of wood surfaces.

Several approaches have been used previously to stabilize wood surfaces. Reaction of chromic acid with lignin model compounds such as guaiacol and catechol indicates that chromic acid photostabilizes wood by reacting with lignin to create photostable lignin complexes enabling energy transfer or energy emittance from wooden surfaces. ${ }^{11,15}$ Ferric compounds also oxidize these lignin model compounds. ${ }^{15,16}$ Iron (III) guaiacol oxidation complexes are water soluble and unable to protect wood from weathering processes, while the counterpart $\mathrm{Cr}(\mathrm{IV})$ guaiacol oxidation complexes are resistant to water leaching and afford weathering protection. ${ }^{11}$ Other inorganic compounds of manganese, titanium, and zirconium were found to be ineffective. ${ }^{17}$ Grafting various benzophenones, ${ }^{2,12}$ antioxidants/hindered amine light stabilizers/phenylethane moieties, ${ }^{18}$ and epoxidized triazine UV absorbers ${ }^{12}$ to wooden surfaces has realized increased photostability of surfaces with performance improvements. While acetylation of wood produces a relatively dimensionally stable acetylated material, ${ }^{19}$ deacetylation and loss of photostability occur with exposure to UV radiation. ${ }^{20,21}$ Esterification of wood with the aromatic acid, benzoyl chloride, was found to photostabilize Scots pine wood but required high-weight gains of up to $70 \%$.

We have used a novel approach to photostabilize Pinus radiata surfaces, through controlled surface delignification, and the results obtained are encouraging. The aim was to achieve partial delignification of cell walls to a depth of $2-3 \mathrm{~mm}$ from the surface while maintaining the integrity of the surface wood tissues in the delignified zone, thereby rendering this region less prone to damage by solar radiation. To achieve this, several chemical surface delignification methods were trialled in the method development process, in an attempt to optimize the extent of delignification, with peracetic acid being chosen as the method for refinement and deployment. A preweathering technique was also used for producing photostabilized boards. This article, Part 1 of a two-part series, reports the characterization of changes in $P$. radiata surfaces, after peracetic acid or accelerated preweathering treatments, using a range of chemical, microscopic, and spectroscopic techniques. Part $2^{22}$ of the series describes the coating of these boards, their accelerated- and exterior weathering performance, and demonstrates their effectiveness in resisting exterior weathering forces.

\section{Experimental}

We employed chemical and preweathering treatments to surface delignify $P$. radiata with the aim to modify board surfaces to obtain photostability. Such surfaces can be clear coated and be expected to show enhanced exterior durability. Peracetic acid was used to chemically delignify the surfaces of boards, and method development and exposure trials continued over six years. In the initial stages of method development two other chemical delignification methods, peroxymonosulfate (oxone) and sodium chlorite, were used to get a comparison with the peracetic acid treatment. From this work we obtained underpinning information regarding the effects of oxidative delignification treatments of wood. This information was centered on analysis of acid-soluble lignin, Klason lignin, carbohydrates plus ${ }^{13} \mathrm{C}$ solid-state NMR analyses. This was not repeated for peracetic acid treatments.

The maturing stage of method development for chemical delignification of boards was focused on peracetic acid treatments only since peracetic acid is nonchlorinated and is thus acceptable environmentally, while chlorite is not. Oxone is also acceptable environmentally, but it was not chosen as our chemical delignification agent of choice because firstly, it required a prewashing step with ethylene-diaminetetra-acetic acid (EDTA) to remove metal ions and secondly, and more importantly, it contains sulfur. Sulfur-reducing bacteria in treatment of waste water can result in the formation of hydrogen sulfur with concomitant highly odorous and objectionable smells.

Microtome-cut sections $(10 \mathrm{~mm} \times 10 \mathrm{~mm} \times 120 \mu \mathrm{m}$; $\mathrm{R} \times \mathrm{L} \times \mathrm{T})$ were treated with sodium chlorite $(1.8 \%$ $\mathrm{m} / \mathrm{v}, \mathrm{pH} 4,70^{\circ} \mathrm{C}$ for $60 \mathrm{~min}$ then $\mathrm{NaOH}(1 \mathrm{M})$ leached at $50^{\circ} \mathrm{C}$ for $60 \mathrm{~min}$, water washed $10 \mathrm{~min}$, two 5 -min washes in $0.1 \mathrm{M} \mathrm{HCl}$, then 15 -min water wash) or 
oxone $\left(10 \% \mathrm{~m} / \mathrm{v}, \mathrm{pH} 4\right.$ at $75^{\circ} \mathrm{C}$ for 120 min then $\mathrm{NaOH}$ leached, and washed as for the chlorite treatment. Pretreatment was with $2.5 \% \mathrm{~m} / \mathrm{v}$ EDTA, $\mathrm{pH} 5.5$, at $90^{\circ} \mathrm{C}$ for $60 \mathrm{~min}$, then water wash for $60 \mathrm{~min}$ ). The samples were analyzed for lignin and carbohydrates, and probed by solid-state NMR spectroscopy. Microtomed samples were used to ensure unhindered access of chemical and reaction with the whole section. They were also useful in characterizing the extent of reaction.

\section{Materials}

Machine-surfaced, kiln-dried, defect-free $P$. radiata sapwood $\left(400 \times 100 \times 20 \mathrm{~mm}^{3} ; \mathrm{L} \times \mathrm{T} \times \mathrm{R}\right.$ and $230 \times$ $\left.60 \times 10 \mathrm{~mm}^{3} ; \mathrm{L} \times \mathrm{T} \times \mathrm{R}\right)$ was used for preweathering and peracetic-acid-surface treatments.

\section{Peracetic acid treatment of wooden boards}

The peracetic acid was generated in situ by addition of $10.5-\mathrm{L} 30 \%$ hydrogen peroxide solution to $25.9-\mathrm{L}$ glacial acetic acid to a 56-L glass container, which was housed inside a 400-L PVC bath. Two thermostatically controlled $3-\mathrm{kW}$ heaters were used to heat the water in the PVC bath to obtain and maintain temperature. The acetic acid was preheated to $35^{\circ} \mathrm{C}$. The exothermic reaction was stabilized by the thermal mass of the surrounding water in the PVC bath. The bath also served as containment vessel for any overflow from the glass reaction vessel. Formation of peracetic acid was monitored by adding KI to a sample and titrating liberated iodine with thiosulfate at regular intervals. ${ }^{23}$ After overnight reaction, the temperature was $44^{\circ} \mathrm{C}$ and peracetic acid concentration was $8.4 \%$ $\mathrm{m} / \mathrm{v}$. The heaters were turned on for $3 \mathrm{~h}$ to reach and maintain $70^{\circ} \mathrm{C}$ at which time the starting peracetic acid concentration for treatment of the wooden boards had increased to $10.7 \% \mathrm{~m} / \mathrm{v}$.

Twenty of the larger and 20 of the smaller boards were filleted and immersed in the peracetic acid solution. After $20 \mathrm{~min}$, the exothermic reaction with the boards resulted in the reaction solution overflowing the sides of the glass vessel. After $40 \mathrm{~min}$ the reaction had stopped; the solution remaining in the reaction vessel was $0.1 \%$. The reaction chamber was diluted with water to keep the samples immersed. The boards were rinsed several times with water and then with $0.1 \mathrm{M}$ sodium hydroxide at $50^{\circ} \mathrm{C}$ for $1 \mathrm{~h}$, rinsed twice with water, followed by a $1-\mathrm{h}$ acetic acid $(0.1 \%, \mathrm{v} / \mathrm{v})$ wash. A second acetic acid wash was then carried out (30 $\mathrm{min})$. The boards were rinsed three times with water. The peracetic acid in the used reaction liquid was neutralized with iron filings. A $7.5 \mathrm{M} \mathrm{NaOH}$ solution was added until neutral $(\mathrm{pH}$ 6-7). This solution could be disposed of through the normal waste-water channels.

\section{Accelerated weathering pretreatment of wooden boards}

Pinus radiata boards were exposed in a xenonarc-accelerated weathering chamber (Atlas Wi65 weatherometer) using a standard cycle of $102 \mathrm{~min}$ of irradiation followed by 18 min of water spray for a period of $450 \mathrm{~h}$.

\section{Drying}

All delignified boards were placed and filleted in a fume hood at room temperature $\left(20-25^{\circ} \mathrm{C}\right)$ for mild drying by ventilation for 21 days.

\section{Methods of characterization}

\section{Digital photography}

Digital photographs were taken of both transverse and tangential faces of the boards following treatment. A phloroglucinol (1,3,5-trihydroxybenzene)- $\mathrm{HCl}$ stainbased on the Wiesner reaction, was used to determine the depth to which the wood had been delignified. ${ }^{24}$ In the Wiesner reaction, phloroglucinol reacts with the coniferaldehyde part of lignin forming a pink/purple color. In the solid wood state, it is not a quantitative determination for lignin, but does serve to highlight partially delignified regions.

\section{Determination of density of a treated surface as a function of depth}

Sequential $30-\mu \mathrm{m}$-thick sections were obtained from the peracetic-acid-treated surface of $P$. radiata blocks $\left(20 \times 10 \times 10 \mathrm{~mm}^{3} ; \mathrm{R} \times \mathrm{L} \times \mathrm{T}\right)$, and then the density of each section was determined as described below. Blocks were cut from one earlywood and one latewood area $\left(10 \times 10 \mathrm{~mm}^{2}\right)$ on the flat-sawn surface (bark side) of a peracetic-acid-treated board and were tangentially sectioned to the depth of the earlywood and latewood bands, respectively. Sampling the blocks in the top $200 \mu \mathrm{m}$ was problematic due to the fibrous nature of the treated surface on sectioning. Block thickness was measured before and after sectioning, with graduated micrometer calipers, after conditioning in a $23^{\circ} \mathrm{C} / 50 \%$ $\mathrm{RH}$ environment. Section thicknesses were determined using a Messmer paper thickness tester ${ }^{25}$ with two parallel circular pressure faces. The sum of earlywood and latewood section thicknesses was normalized to the difference measured with the calipers on their respective solid wood blocks. The normalization was applied through adjustment of individual section thickness. Densities of individual sections were then calculated. 


\section{Microscopy}

For light microscopy, sliding microtome sections, $60-\mu \mathrm{m}$ thick, were cut perpendicular to the surface of the board. Three sections were taken from three places on each board sampled. Sections of peracetic-acid-treated and preweathered samples were taken from boards, which had been coated with a reactive isocyanate primer (Uroxsys Ltd., New Zealand; Duracoat brand) and topcoated with a Bayer A665 acrylic polyurethane to prevent surface tissues from detaching during sectioning. A few drops of water were placed on the wood surface to moisten it just prior to sectioning, as sectioning of hard dry surfaces of wood can cause severe tissue distortion. The sections were stained with $1 \%$ phloroglucinol in $95 \%$ ethanol in combination with a few drops of concentrated $\mathrm{HCl}$ to contrast lignin in wood cell walls. The stained sections were mounted in glycerol on a glass slide, and examined and photographed using a Zeiss Axiovert 200 inverted microscope.

For transmission electron microscopy (TEM), the hand sections taken for light microscopy were cut into smaller pieces, dehydrated in an acetone series, and embedded in Spurr's low viscosity resin. ${ }^{26}$ Ultrathin sections were cut with an ultramicrotome using a diamond knife, stained with $1 \%$ potassium permanganate (prepared in $0.1 \%$ sodium citrate), and then examined with a Philips 300 TEM. For assessment of increases in cell wall porosity due to peracetic acid treatment, ultrathin sections were sequentially stained with potassium permanganate, aqueous uranyl acetate $(2 \%, v / v)$, and lead citrate $(2 \%, v / v)$. This combination of stains, which we developed specifically to enhance the contrast of delignified cell walls, provided a contrast of cell wall superior to that achieved by potassium permanganate alone.

Light microscopy (LM) showed extensive cell separation in the preweathered treated samples, whereas in the peracetic-acid-treated samples, partial cell separation occurred only in cells in the 1-2 outermost rows and separation did not appear to be complete. To confirm this, as well as to examine the residual lignin in cell walls, TEM work was undertaken only on the peracetic-acid-treated samples.

\section{Infrared determination of depth of treatment}

A Bruker Vector 33 infrared spectrometer, with diffuse reflectance and microscope accessories, was used to acquire diffuse reflectance and attenuated total reflectance (ATR) spectra, respectively, from each section. Peracetic-acid-treated earlywood and latewood samples were consecutively sectioned with a microtome from the treated tangential earlywood and latewood surfaces, to a depth of $3000 \mu \mathrm{m}$. Sections were nominally $60-\mu \mathrm{m}$ thick and had not been mounted in glycerol. The preweathered surfaces of solid wood blocks were examined using a diffuse reflectance accessory.
Spectral data analysis

Spectra were background-corrected. The peak heights and areas of the 1510 and $1739 \mathrm{~cm}^{-1}$ peaks (lignin skeletal aromatic and ester carbonyl vibrations respectively) of the peracetic-acid-treated samples were calculated relative to both the $899 \mathrm{~cm}^{-1}$ peak (cellulose $\beta-1,4$ linked xylopyranose backbone-anomeric carbon group frequency in cellulose and hemicellulose) and the $1370 \mathrm{~cm}^{-1}$ peak (cellulose $\mathrm{CH}$ deformations).

The depth-profile infrared measurements were made using both attenuated total reflectance and diffuse reflectance accessories. The relative peak area intensity changes of the $1510 \mathrm{~cm}^{-1}$ lignin band were more reliable than those calculated using the $1739 \mathrm{~cm}^{-1}$ carbonyl ester peak (Figs. 1 and 2). The $899 \mathrm{~cm}^{-1}$ cellulose internal reference peak area was used for diffuse reflectance measurements, while both 899 and $1370 \mathrm{~cm}^{-1}$ peak areas were used as references for the ATR measurements. Relative peak heights were generally unsatisfactory for diffuse reflectance; however, they were satisfactory for ATR in all cases with the $1370 \mathrm{~cm}^{-1}$ peak and usually with the $899 \mathrm{~cm}^{-1}$ peaks. The area envelope defined for the $899 \mathrm{~cm}^{-1}$ cellulose band areas also spanned a small shoulder peak, possibly due to a mode attributable to glucomannan.

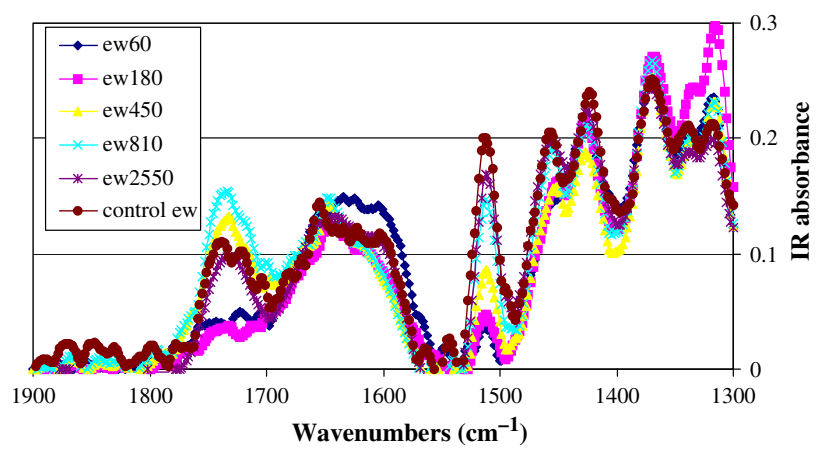

Fig. 1: Earlywood ATR spectra as a function of depth (peracetic-acid-treated wood)

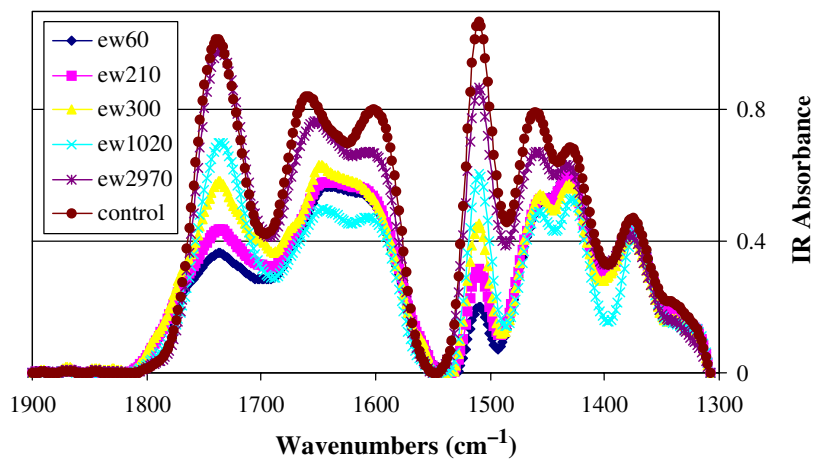

Fig. 2: Diffuse reflectance earlywood spectra as a function of depth (peracetic-acid-treated wood) 


\section{Acetyl bromide lignin analysis as a function of depth}

The average weight of the samples, which were tangential sections obtained with a microtome, was about $5 \mathrm{mg}$ each. This sample mass was not enough for Klason lignin measurement. ${ }^{27,28}$ To determine lignin content in small wood samples, an acetyl bromide procedure and a spectrophotometer were used. ${ }^{29}$ An extractive-free sample of wood meal, ground to 80 mesh was used, with acetyl bromide in acetic acid. Elsewhere, in another lignin determination of small pulp samples $(25-35 \mathrm{mg})$, $25 \%$ acetyl bromide reagent was used and the pulp samples ground to pass though a 20-mesh screen. ${ }^{30}$

In our work, an acetyl bromide lignin method ${ }^{31}$ was modified slightly for application in the analysis of microtomed sections. A mass of 7-14 mg of sections was collected for each acetyl bromide analysis. Samples were aggregated from successive sections until the 10-14 mg mass was achieved and the average depth of these sections used as the depth of the sections. Sample veneers were oven-dried at $55^{\circ} \mathrm{C}$ and results expressed on this basis. Samples were extracted with dichloromethane $(3 \mathrm{~h})$ prior to analysis to avoid a contribution of extractives to lignin values.

\section{Klason lignin and carbohydrate analyses}

Chlorite-treated microtomed sections were ground to pass a 60 -mesh sieve in a Wiley mill. They were then hydrolyzed using $72 \%$ sulfuric acid. The Klason lignin was determined gravimetrically ${ }^{27}$ and acid-soluble lignin analyzed. ${ }^{32}$ The carbohydrate components were analyzed using a Dionex ion chromatography system. ${ }^{33}$

\section{Solid-state nuclear magnetic resonance}

Oxone-treated microtome-cut sections were ground in a Wiley mill to pass a $60-$ mesh sieve. The ${ }^{13} \mathrm{C}$ cross polarization-magic angle spinning (CP-MAS) spectra were obtained on a Bruker AC-200 instrument operating at $50.3 \mathrm{MHz}$ using a contact time of $1 \mathrm{~ms}$. The samples were spun at $2.5 \mathrm{KHz}$.

\section{Results}

The peracetic-acid-treated boards could be characterized using the full suite of microscopic and chemicalbased methods employed. Characterization of the preweathered boards was limited because delignification was confined to only a few outer cell layers. Consequently, no characterization as a function of depth was possible.

\section{Appearance of treated boards}

The treated boards (from both peracetic acid and preweathering treatments) were paler in color than the

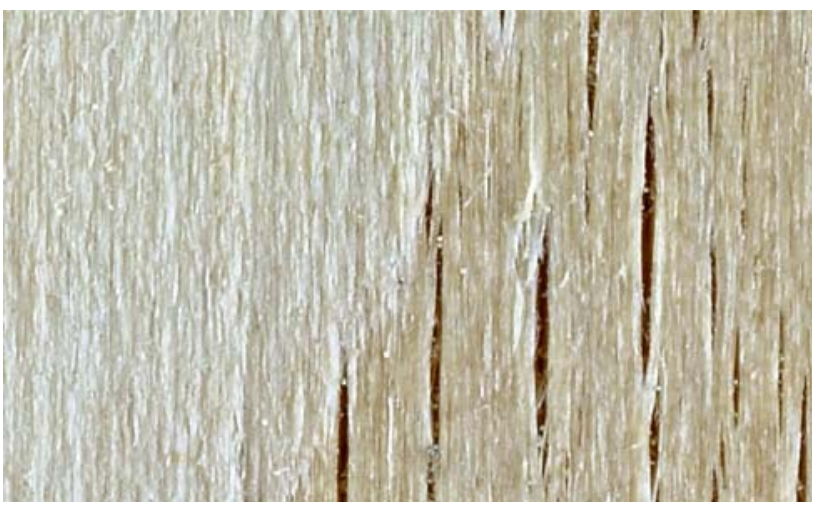

Fig. 3: Latewood more heavily checked than earlywood following peracetic acid treatment

untreated boards. The peracetic acid treatment caused the surface of boards to check, with the latewood being more heavily checked than the earlywood (Fig. 3). Extended peracetic acid treatment times resulted in a furry and loose fibrous surface, which was absent with normal treatment times. As determined by staining of boards with phloroglucinol- $\mathrm{HCl}$ solution, chemical delignification extended to $2-3 \mathrm{~mm}$ deep from the surface (not illustrated). The depth to which cells were delignified by preweathering could not be visually determined using the staining method.

\section{Microscopic characterization of delignified surface tissues}

Light and transmission electron microscopy of transverse sections taken through the edges of peraceticacid-treated boards confirmed visual assessment of delignification, in addition to providing information on the anatomical and ultrastructural characteristics of delignified tissues.

Light microscopy (LM) in combination with phloroglucinol-HCl staining of sections revealed that the zone which visibly appeared clear in peracetic-acidtreated boards consisted of about 25-30 outermost layers of unstained cells (about $1500 \mu \mathrm{m}$ deep) (Fig. 4). In comparison, cell walls in untreated boards displayed a fairly uniform intensity of bright red color (not illustrated). Cell walls in deeper layers from the surface of peracetic-acid-treated boards (layers more than 40 cells deep) displayed a similar color and intensity to that in the cell walls of control panels, and could thus serve as a useful base for comparing the color of cell walls in sections of surface regions within the same section (Fig. 4). Tracheids in the surface layers of peracetic-acid-treated boards tended to separate in the region of the compound middle lamella (the term "compound middle lamella" is used here to denote middle lamella proper plus the primary cell wall), but this was confined to the outer one to two layers that were probably most delignified (Fig. 4). In some cases, 


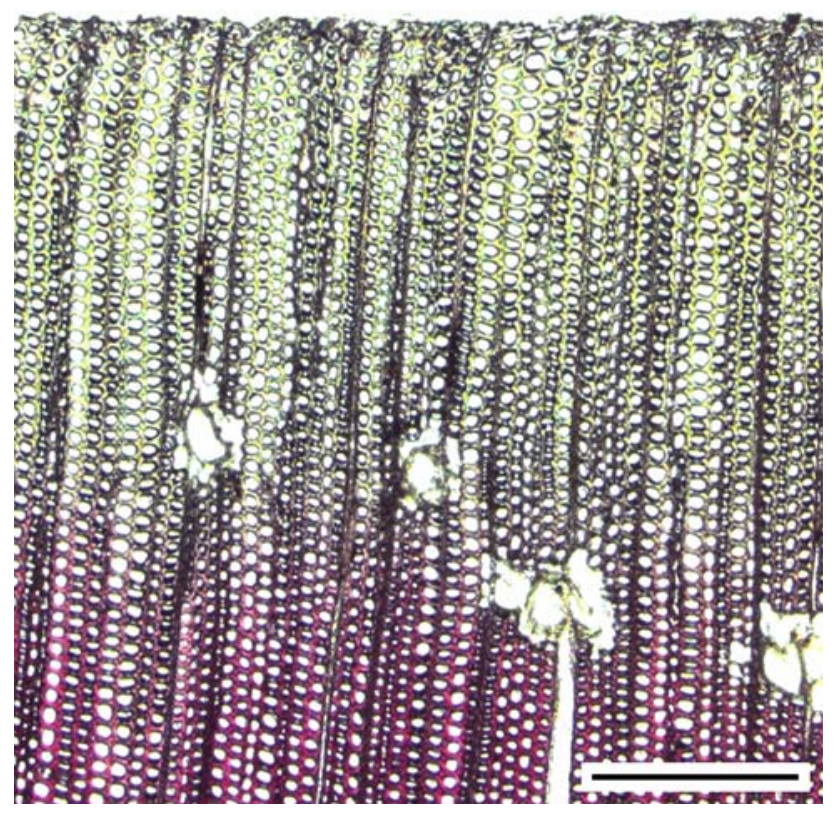

Fig. 4: Light micrograph of phloroglucinol-HCl stained transverse section through a peracetic-acid-treated, reactive-primed, and PU-topcoated board surface. Unstained or lighter stained regions are delignified. Bar $=\mathbf{5 0 0} \mu \mathrm{m}$

rays in the sections taken from peracetic-acid-treated panels appeared unusually wide (Fig. 4), reflecting the effect of peracetic acid also on ray components. Compared to the peracetic-acid-treated boards, the depth of delignification in the preweathered boards extended to only $100-150 \mu \mathrm{m}$ deep from the surface (Fig. 5). Cells in the delignified region (not stained with phloroglucinol- $\mathrm{HCl}$ solution) were also deformed.

\section{Transmission electron microscopy (TEM)}

TEM observations were made only on peracetic-acidtreated boards. (TEM observations of weathered $P$. radiata wood surfaces have been presented elsewhere. ${ }^{34}$ ) The use of TEM greatly extended LM observations, providing information on ultrastructural features of tracheid walls in the surface layers of boards where delignification from chemical pretreatment was greatest as well as of tracheid walls in deeper layers of cells, representing early to intermediate stages of delignification.

Typical ultrastructural features of various cell wall regions in untreated wood after staining with potassium permanganate, a reagent widely used in ultrastructural studies to contrast lignin in cell walls, are shown in Fig. 6. The density of the cell wall is greatest in the middle lamella, reflecting its high lignin concentration. The density of the secondary wall is markedly lower, with the $S_{2}$ layer appearing fairly uniform in density. The $\mathrm{S}_{3}$ layer is thin and lined with warts (tiny, dense projections) that are regarded to be highly lignified. Figure 7 represents early cell wall delignification in the

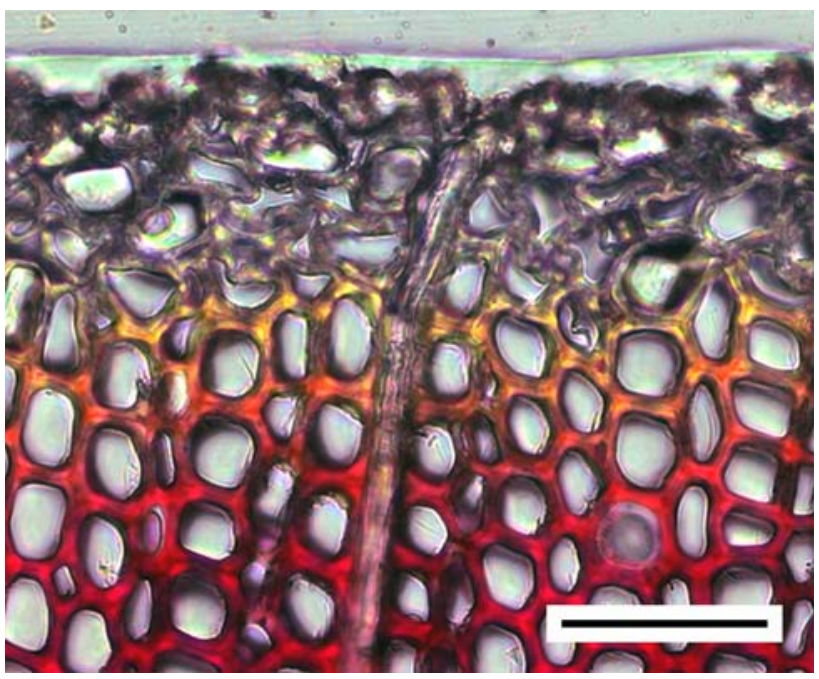

Fig. 5: Light micrograph of phloroglucinol-HCl stained transverse section through a preweathered treated, reactive isocyanate-primed, and PU-topcoated board surface. The delignified region is confined to the surface layer, where cells are distorted. Bar $=100 \mu \mathrm{m}$

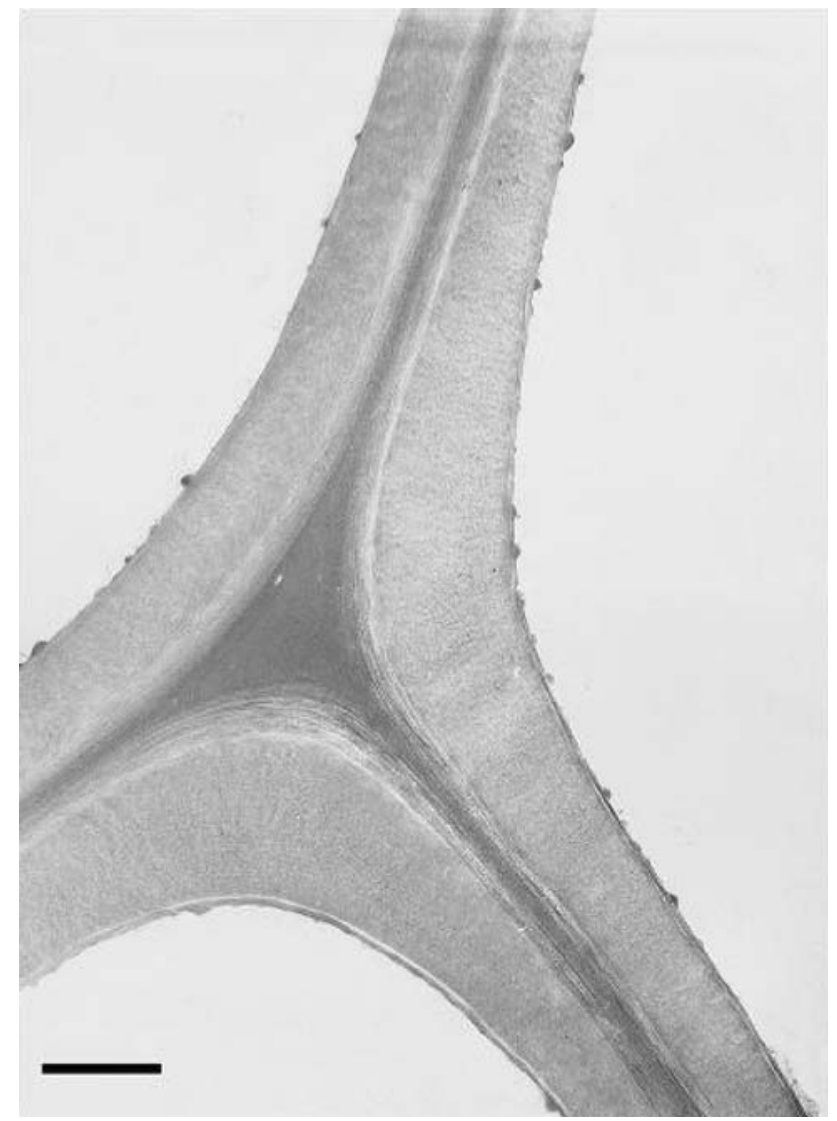

Fig. 6: Low magnification TEM micrograph showing typical appearance of untreated tracheid walls of untreated $P$. radiata in terms of staining characteristics of various cell wall regions. $\mathrm{KMnO}_{4}$ staining. Bar $=2 \mu \mathrm{m}$ 


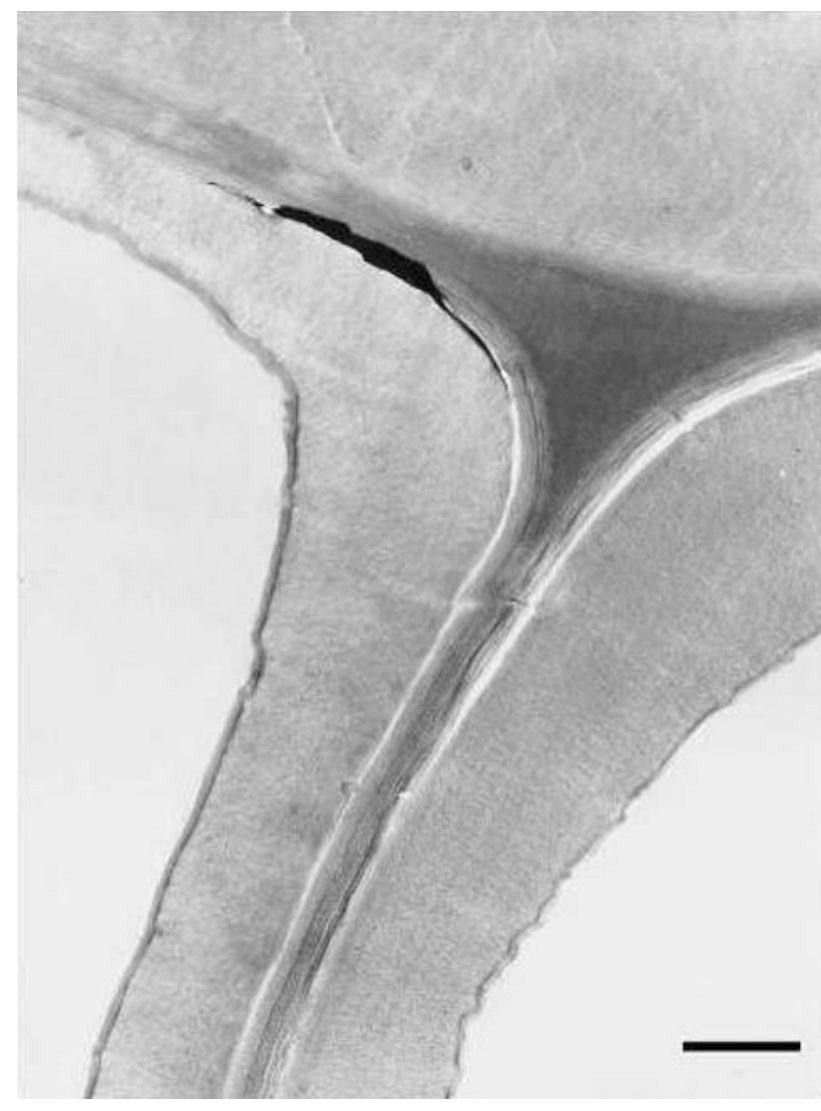

Fig. 7: TEM micrograph of peracetic-acid-treated $\boldsymbol{P}$. radiata, showing early stages of delignification in cell wall. The cell walls are patchy, with some areas appearing lighter than others. $\mathrm{KMnO}_{4}$ staining. Bar $=2 \mu \mathrm{m}$

subsurface region as the ultrastructural and density characteristics of cell walls would indicate. Compared to control, the density of cell corner middle lamella is greater, presumably reflecting a greater penetration of $\mathrm{KMnO}_{4}$ into the cell wall and/or its reactivity with the modified lignin. Elsewhere the middle lamella shows irregularities in its density, being mottled and stripy, an indication that the loss of lignin from these cell wall regions is irregular. Patchiness in the cell wall is also apparent for the $S_{2}$ layer, arising from local variability in the density of cell wall, again pointing to inhomogeneous losses in lignin. Compared to control, the $S_{3}$ layer is markedly denser, lacks the warts, and shows kinks in places, all pointing to a change in the fine structure and properties of this layer caused by peracetic acid treatment. The $S_{2}$ layer has separated from the $S_{1}$ layer due to a fracture in the region of interface between the two layers, indicating that this region may be most susceptible to damage from mechanical stresses imposed during sample preparation for electron microscopy. Figure 8 illustrates advanced stages of delignification. The cells in view were imaged by TEM from a section taken through the outermost layer of a peracetic-acid-treated panel, which did not react with phloroglucinol-HCl. The cell

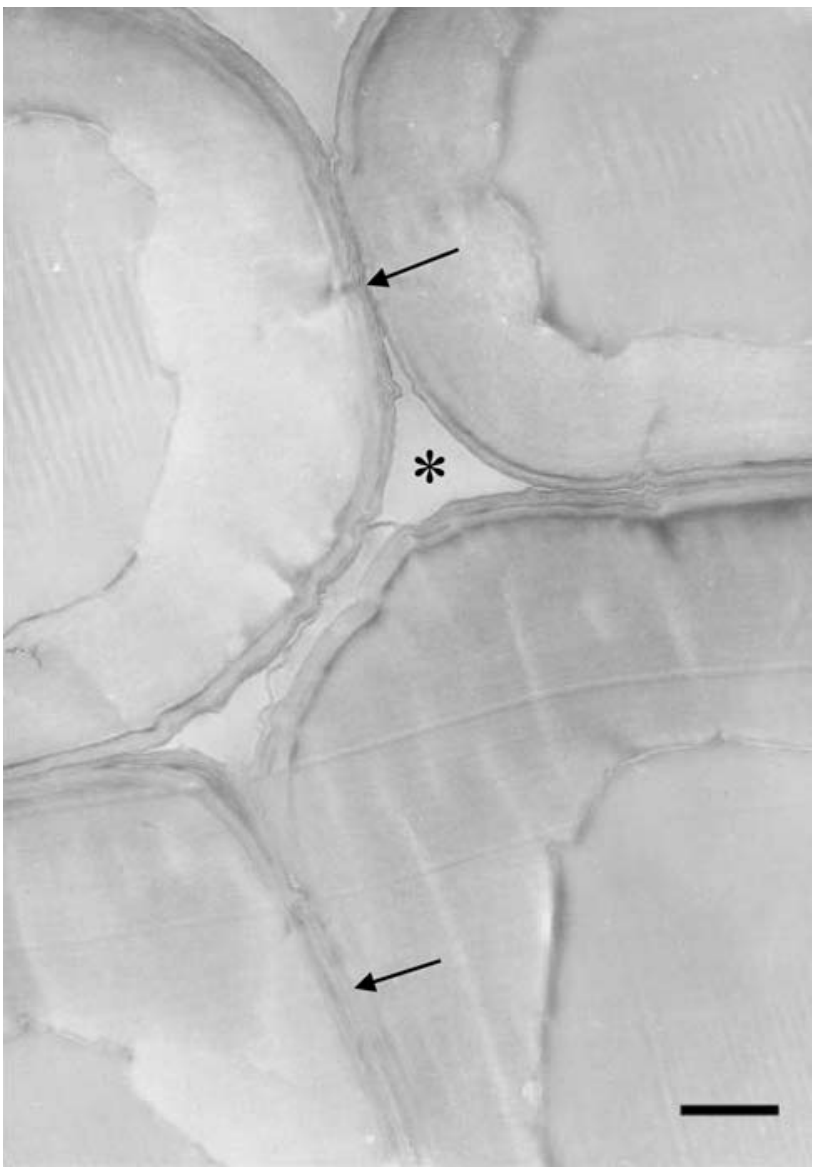

Fig. 8: TEM micrograph of tracheids in the surface layers of peracetic-acid-treated $\boldsymbol{P}$. radiata. Lignin has been removed from the cell corner middle lamella, and the adjoining tracheids have separated in this region $\left({ }^{*}\right)$. However, tracheids are still joined in other middle lamella regions (arrows). The secondary walls have also lost much of their lignin, judging by their electron-lucent appearances. Warts are no longer present. $\mathrm{KMnO}_{4}$ staining. Bar $=2 \mu \mathrm{m}$

walls appear to have lost much of their lignin, judging by their poor affinity for $\mathrm{KMnO}_{4}$, which was used to contrast lignin in the cell walls. The cells have separated in the region of cell corner middle lamella, an indication that the loss in lignin from this cell wall region was too extensive for the neighboring cell walls to maintain adhesion in the corner. Adjoining tracheids are still joined in the middle lamella region between cell corners, pointing possibly to a greater resistance of lignin in this region to peracetic acid treatment than lignin in the cell corner middle lamella. Cell walls are markedly swollen, as the wavy appearance of their inner faces would indicate.

\section{Density of treated surface envelope as a function of depth}

The density of earlywood in microtome-cut sections increased rapidly from $300 \mu \mathrm{m}$ in depth to about 


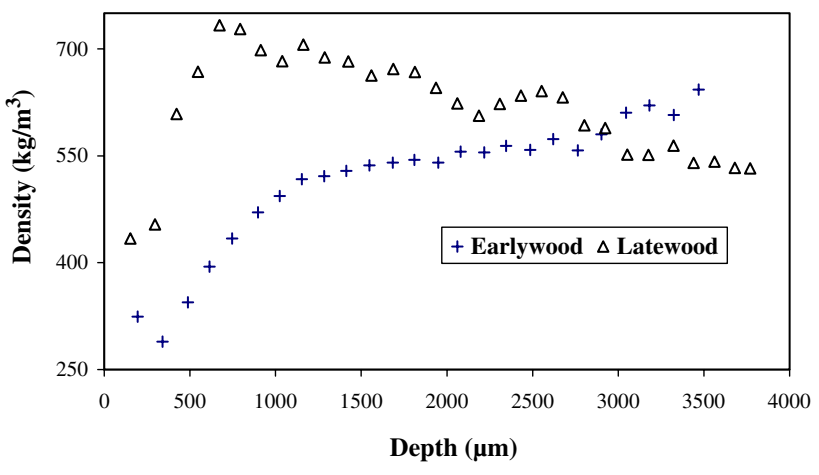

Fig. 9: Density of surface envelope of peracetic-acidtreated sample as a function of depth

Table 1: Analysis of acetyl bromide lignin on mature pine QC samples

Number of samples

Average

26.6

Standard deviation

0.41

Coefficient of variance

$1.6 \%$

$1200 \mu \mathrm{m}$ and then increased slowly with depth to $3500 \mu \mathrm{m}$ (Fig. 9). Latewood densities rose rapidly to a depth of $700 \mu \mathrm{m}$ and then decreased with depth to $3500 \mu \mathrm{m}$.

\section{Acetyl bromide lignin analyses}

A sequence of preliminary acetyl bromide lignin analyses were performed on 24 quality-controlled (QC) mature pine samples to quantify the $95 \%$ confidence interval for the lignin content determined by the acetyl bromide method. The lignin content of the same mature pine QC sample was established as $26.6 \%$ using the Klason lignin $\operatorname{method}^{27}$ (Table 1). The limits for sample mass for lignin measurement were 7 to $14 \mathrm{mg}$. Lignin results were not reliable if the sample mass was outside this range. The mean acetyl bromide lignin content of the QC samples in each analytical set was lower than the $95 \%$ confidence interval established for the QC, but the duplication of samples was good $(< \pm 5 \%)$. A modified acetyl bromide method with adjustment of the absorptivity of lignin from 23.3 to $20.0 \mathrm{~L} \mathrm{~g}^{-1} \mathrm{~cm}^{-1}$ for $P$. radiata wood meal, bisulfite pulp, and Kraft pulp has been reported. ${ }^{35}$ In the current work, adjustment of the QC sample data was also carried out, by adjusting the absorptivity value of lignin to $18.5 \mathrm{~L} \mathrm{~g}^{-1} \mathrm{~cm}^{-1}$, to a Klason lignin content of $26.6 \%$ and this value was then applied to the other samples in the same analytical set.

The analytical lignin data for earlywood and latewood, in peracetic-acid-treated boards, as a function of depth are fairly similar with earlywood and latewood lignin concentrations in the top $120 \mu \mathrm{m}$ from the

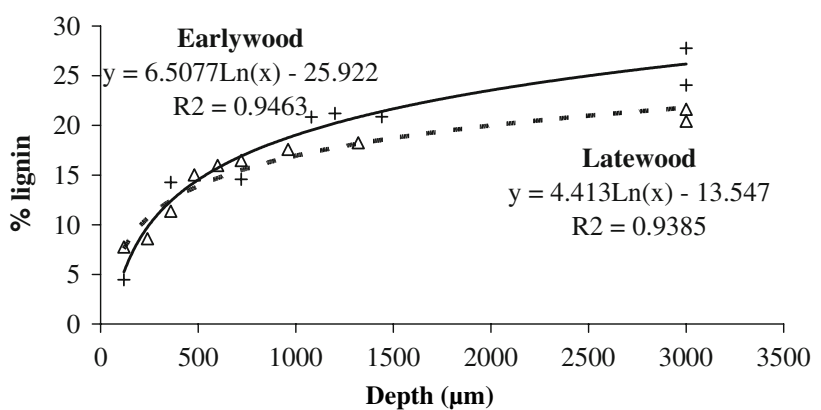

Fig. 10: Lignin content of earlywood and latewood bands of peracetic-acid-treated sample as a function of depth as determined by acetyl bromide analyses

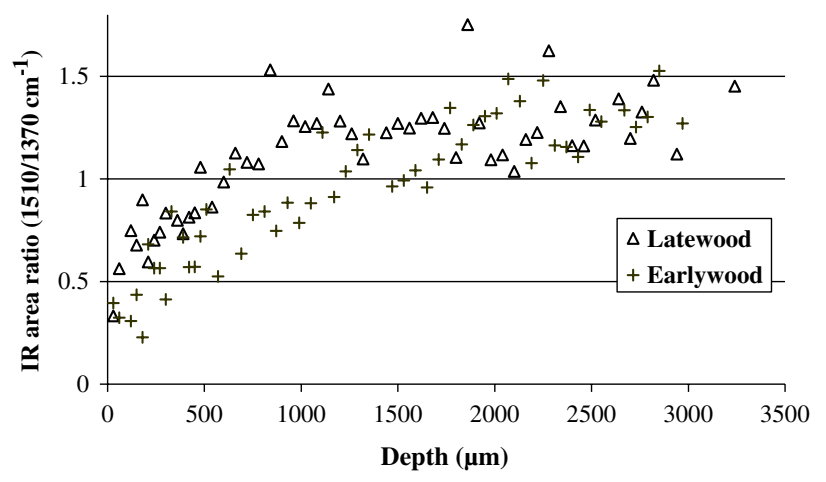

Fig. 11: ATR peak areas: earlywood and latewood internal IR ratios $\left(1510 / 1370 \mathrm{~cm}^{-1}\right.$ ) with depth (peracetic-acid-treated wood)

treated surface being $4 \%$ and $8 \%$, respectively, increasing logarithmically to maxima of $25 \%$ and $21 \%$, respectively, reflecting untreated wood baseline levels at distances from the surface of between 2 and $3 \mathrm{~mm}$ (Fig. 10).

\section{Infrared spectral analysis}

Using ATR relative peak areas of $1510 \mathrm{~cm}^{-1}$ (lignin) and $1370 \mathrm{~cm}^{-1}$ (cellulose), the amount of lignin increased from the surface to a depth of about 2000$2500 \mu \mathrm{m}$ for earlywood or just over $1000 \mu \mathrm{m}$ for latewood (Fig. 11). These data contain a lot of scatter. For diffuse reflectance relative peak areas of the $1510 \mathrm{~cm}^{-1}$ (lignin) and $899 \mathrm{~cm}^{-1}$ (cellulose) peaks (Fig. 12), the corresponding depths were 1600 and $1000 \mu \mathrm{m}$ (Fig. 10). These data displayed less scatter than the ATR data. The earlywood and latewood control relative intensities for the ATR data suggested that the lignin content continued to increase beyond the $3000 \mu \mathrm{m}$.

The infrared spectra of the preweathered samples (data not shown) indicated complete removal of surface lignin. After both 135- and 450-h exposure, the lignin bands at 1600 and $1505 \mathrm{~cm}^{-1}$ (stretching 


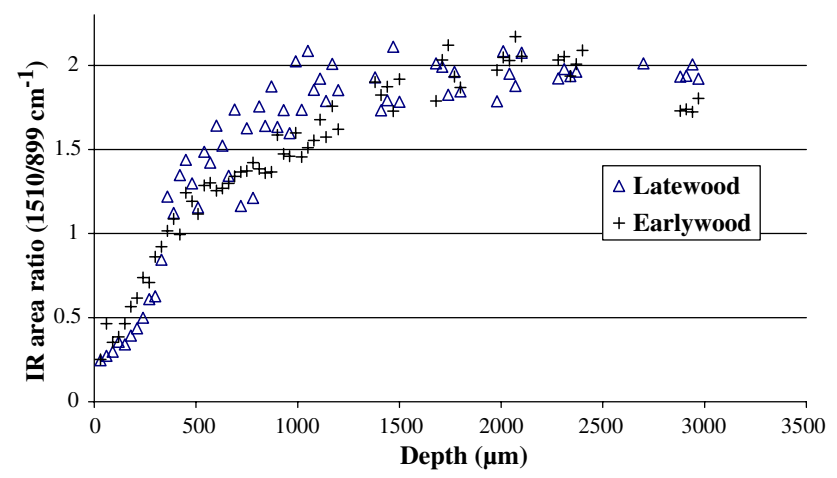

Fig. 12: Diffuse reflectance peak areas: earlywood and latewood internal IR ratios $\left(1510 / 899 \mathrm{~cm}^{-1}\right)$ with depth (peracetic-acid-treated wood)

vibrations of carbon-carbon double bond in lignin aromatic ring) and $1268 \mathrm{~cm}^{-1}$ (carbon-oxygen stretching vibration in lignin) were absent.

\section{Klason lignin and carbohydrate analyses}

In the early method development, oxone and chlorite were used as treatments in order to obtain underpinning information on what changes were occurring in the wood on chemical treatment. Chlorite- and oxonetreated microtome sections all showed a reduction in the amount of Klason lignin compared to the untreated control, which is consistent with a partial surface delignification. For the chlorite-/oxone-treated samples, $33 \%$ of the Klason lignin has been removed (Table 2). The inclusion of the sodium hydroxide extraction step after oxidation treatment further increases the extent of delignification and glucose content. The amount of acid-soluble lignin in the treated samples is greatly increased over that of the control sample. This is probably due to degradation of some of the hydroxyl substituted aromatic rings of the native lignin structure by the oxidative treatment. Thus, in aqueous sulfuric acid solution, the traditional method of determining Klason lignin, crosslinking of the hydroxyl functional groups and ether linkages to give the water-insoluble Klason lignin fraction does not occur. More polar phenyl compounds are then transferred to the filtrate and absorb strongly in the ultraviolet region, giving a large acid-soluble lignin content.

\section{${ }^{13} \mathrm{C}$ cross polarization-magic angle spinning (CP-MAS) spectra}

The main features of the ${ }^{13} \mathrm{C} \mathrm{CP}-\mathrm{MAS}$ spectra are assigned in Table 3. ${ }^{36,37}$ In the oxone-treated/waterwashed microtomed sections, the relative intensity of both the lignin/hemicellulose methoxy band at $56 \mathrm{ppm}$ and the lignin guaiacol $\mathrm{C}-1, \mathrm{C}-3$, and $\mathrm{C}-4$ position absorptions at $150 \mathrm{ppm}$ to the cellulose absorption bands (C-1, C-4, C-6, and C-2,3,5 positions) is less than for the control sample (Fig. 13). The 56- and 150-ppm lignin bands in the alkaline-extracted samples are smaller, again suggesting further lignin removal on alkaline extraction. In the spectrum of oxone-treated/ alkaline-washed sections, the absence of two bands, namely the methyl carbon at $21 \mathrm{ppm}$ and the carbonyl carbon at $173 \mathrm{ppm}$, suggests deacetylation of hemicelluloses as a consequence of hydrolysis during the alkaline washing. Both the C-4 and C-6 noncrystalline cellulose absorption bands at 84 and $63 \mathrm{ppm}$, respectively, are both reduced in relative intensity compared

\begin{tabular}{lc}
$\begin{array}{l}\text { Table 3: Solid-state } \\
\text { assignment }\end{array}$ & NMR ${ }^{13} \mathbf{C}$ chemical shifts and \\
Chemical shift (ppm) & \multicolumn{1}{c}{ Assignment ${ }^{37}$} \\
\hline Celluloses & \\
63 & C-6 noncrystalline cellulose \\
66 & C-6 interior or crystalline cellulose \\
72,74 & C-2,3,5 glucose units in cellulose \\
84 & C-4 noncrystalline cellulose \\
89 & C-4 interior or crystalline cellulose \\
105 & C-1 glucose units in cellulose \\
Lignin & \\
134 & C-1 of guaiacyl groups \\
148 & C-3 of free phenolic groups \\
148 & C-3 and C-4 guaiacyl groups \\
152 & C-4 of etherified guaiacyl groups
\end{tabular}

Table 2: Effect of chemical delignification treatment on $\boldsymbol{P}$. radiata cell wall composition

\begin{tabular}{lccccccr} 
Treatment & \% of Klason Lignin & \% of Acid-soluble lignin & $\%$ Ara & \% Gal & $\%$ Glu & $\%$ Xyl & \% Mann \\
\hline Control & 26.3 & 0.39 & 1.05 & 1.61 & 39.3 & 4.77 & 10.6 \\
$\mathrm{NaClO}_{2} / \mathrm{H}_{2} \mathrm{O}^{\mathrm{c}}$ & 17.5 & 3.41 & 1.16 & 2.06 & 41.4 & 5.12 & 10.2 \\
$\mathrm{NaClO}_{2} / \mathrm{NaOH}$ & 13.6 & 2.28 & 1.19 & 2.13 & 47.9 & 4.87 & 11.0 \\
$\mathrm{Oxone} / \mathrm{H}_{2} \mathrm{O}$ & 15.3 & 2.84 & 1.02 & 1.78 & 40.6 & 4.89 & 8.8 \\
Oxone $/ \mathrm{NaOH}$ & 13.2 & 1.44 & 0.92 & 1.96 & 52.2 & 4.89 & 11.2 \\
\hline
\end{tabular}

${ }^{a}$ All results are expressed in $\mathrm{g} / 100 \mathrm{~g}$ (w/w; total sample weight)

b Abbreviations: Ara $=$ arabinose, $\mathrm{Gal}=$ galactose, $\mathrm{Glu}=$ glucose, $\mathrm{Xyl}=$ xylose, Mann $=$ mannose

${ }^{c}$ Either water wash only or $\mathrm{NaOH}$ wash followed by water 


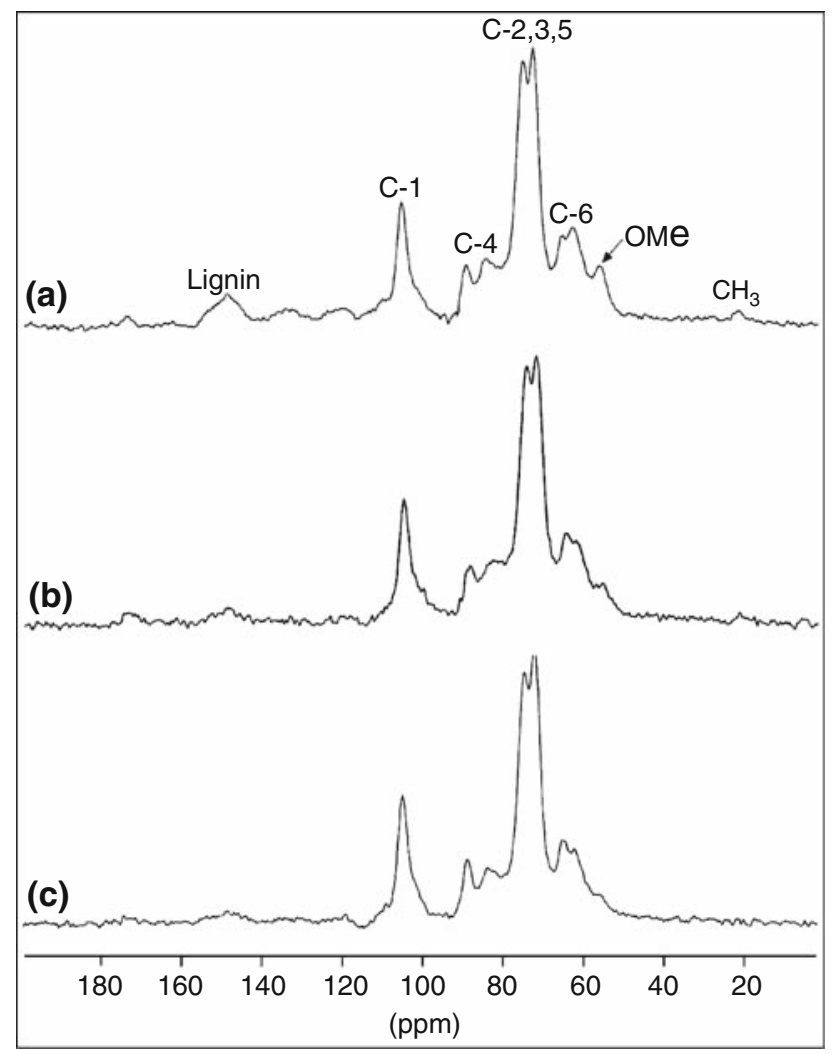

Fig. 13: ${ }^{13} \mathrm{C}$ NMR CP/MAS solid-state spectra of $P$. radiata microtome-cut sections. A: untreated state (control); B: oxone-treated/water-washed and C: oxone-treated/alkalinewashed

with the cellulose absorption bands for the C-4 and C-6 cellulose absorption bands in the control sample.

\section{Discussion}

It is apparent from the information presented that the aim of our work to obtain partial delignification in the surface layers of boards, without compromising the structural integrity of wood tissue, has been achieved. Phloroglucinol staining of boards and light microscopy of sections taken through the surface regions of peracetic acid boards provided evidence of cell wall delignification to the desired depth from the surface. A combination of microscopy and chemical characterization provided valuable complementary information, revealing cellular characteristics and compositional changes of the delignified zone in addition to the extent and depth of delignification achieved.

The accelerated preweathering method was ideal for achieving cell wall delignification without "pulping" the wood, but the delignification was confined to only the outer 3-4 cell layers. This depth may be sufficient from the point of view of protection from solar radiation as well as coating adhesion via mechanical interlocking. However, compared with the chemical treatment employed, the preweathering method required a much longer (weeks vs hours) period, and therefore this could be a deterrent to its practical application.

Surface checking was a prominent feature of the appearance of peracetic-acid-treated boards. The checking, which was more prominent in the treated latewood, showed most strongly when boards were dried. As the surface dries quickly, the core remains at higher moisture content for some time. As a result, the surface attempts to shrink but is restrained by the core. This restraint causes tensile stresses at the surface, which, if large enough, can pull the fibers apart creating a check. ${ }^{38,39}$ This process is more pronounced in the latewood since the thicker latewood cell walls are relatively inflexible and so shrinkage stresses are only released through the physical check formation. Checks were also present in the earlywood but they were not as pronounced as in the latewood. This is because the thinner earlywood cell walls are more flexible and can accommodate some of the shrinkage stress. The points of origin of checking as seen on the tangential faces of boards are the thin-walled, nonlignified parenchyma cells in the rays that do not have sufficient strength to resist drying stress. The chemical treatment may have affected rays, enhancing the susceptibility of ray cells to checking in the delignified boards. The control boards, which were taken through the treatment process with the medium being only water, did not check. The peracetic acid treatment is therefore a major contributor to check development. However, this may not be a disadvantage, as the pores (checks) in the surface are likely to be filled with the coating when boards are coated and the surfaces thus stabilized.

The information obtained from the methods for characterizing the substrate produced, as well as the substrate itself, needs to be examined and evaluated in greater detail. The increase in density in earlywood with depth (Fig. 9) is consistent with a chemical delignification process that is most pronounced at the board surface, extending to a depth of $1200 \mu \mathrm{m}$. Beyond this depth, the density is relatively unaffected until about $3000 \mu \mathrm{m}$, where the observed increase in the density is likely to represent the beginning of a transition to a higher density latewood band. The observed trend in density with depth in the latewood band is likely to be related to the following two factors. Firstly, there is a surface reduction in density to a depth of $700 \mu \mathrm{m}$ as a result of chemical treatment and, secondly, there is a natural decreasing trend in the density of latewood. It has been shown by Silviscan analysis that latewood density in $P$. radiata decreases across individual bands from bark to pith. ${ }^{40-42}$ A further possibility for the initial surface decrease in density in the latewood band is that the latewood section was overlaid with one or two cell layers of earlywood of considerably lower density and which may have been delignified as well.

Characterization of the extent of delignification in the board surfaces, from visual to subcellular levels, 
was achieved by a combination of staining and microscopic methods. The envelope around the crosssection of the peracetic-acid-treated board that had not stained with phloroglucinol and the staining pattern of microtome-cut sections (Fig. 4) show reasonably welldefined areas of partially delignified wood produced from a batch-immersion process, providing evidence of an envelope delignification possibly achieved through controlled solution diffusion processes. Visual detection of delignification on the preweathered surfaces was not possible using the phloroglucinol stain, indicating that the depth of delignification was limited to the surface to a maximum of perhaps $200 \mu \mathrm{m}$ or so, as observed by light microscopy (Fig. 5). This would also be consistent with the reported depth of penetration of ultraviolet radiation to about $75 \mu \mathrm{m}$ into wood. ${ }^{43}$ Photochemical degradation has been estimated to occur from 200 to $2540 \mu \mathrm{m} .{ }^{43}$ The limitation of phloroglucinol staining, and particularly of boards, means that this staining method is restricted to being a screening tool for detecting gross changes in lignin content. However, phloroglucinol staining of sections in conjunction with light microscopy enabled us to more precisely determine the depth to which delignification had occurred in both peracetic-acid-treated and preweathered boards. $\mathrm{KMnO}_{4}$ staining of cell walls in conjunction with TEM is useful to probe the extent and pattern of delignification of wood at individual cell and cell wall levels. The ultrastructural observations presented using $\mathrm{KMnO}_{4}$ staining provided evidence that in the surface regions of peracetic-acid-treated boards lignin was completely removed from the cell corner middle lamella regions, though cells were still joined in other regions of middle lamella. TEM also showed that the secondary wall layers were also delignified; however, the integrity of these cell wall layers was maintained.

The acetyl bromide lignin analyses are consistent with a diffusion-controlled delignification process occurring in the treatment bath. The concentration of lignin to depths of $1500 \mu \mathrm{m}$ is similar for both earlywood and latewood (Fig. 10) before reaching slightly different levels at $3000 \mu \mathrm{m}$. Earlywood is reported to have a higher lignin concentration than latewood for Douglas fir and red pine, ${ }^{45}$ which may be related to differences between earlywood and latewood in the proportion of middle lamella to secondary wall.

A second semiquantitative measure of lignin content with depth was obtained using the relative intensities of the infrared diffuse reflectance absorption spectra $\left(1510 \mathrm{~cm}^{-1} / 899 \mathrm{~cm}^{-1}\right)$. The trend in plotted values (Fig. 11) closely resembles that of the acetyl bromide lignin data. The relationship between depth of photodegradation, penetration of light into a wooden surface and wood density using infrared spectroscopy has been studied. ${ }^{44,46,47}$ It was concluded that there is an inverse relationship between photodegradation and wood density that can be understood by the attenuation of light that occurs in the surface layers of wood exposed to UV and visible light and that this explains the higher rates of erosion of earlywood compared to latewood.

The infrared data for peracetic-acid-treated and preweathered samples are consistent with delignification being the dominant process in both these treatments. Concomitant changes occurring alongside delignification, however, greatly increased hot water solubility of untreated $P$. radiata veneers after weathering. ${ }^{3}$ The presence of mannose and xylose in the extract from weathered veneer was indicative of galactoglucomannan and arabinoglucuronoxylan hemicelluloses being the dominant hemicelluloses in $P$. radiata. ${ }^{3,48}$ A greatly reduced holocellulose concentration in weathered samples confirmed hemicellulose degradation since cellulose levels were reduced by only a minor amount.

The amount of Klason and acid-soluble lignin for the untreated control sample is in agreement with that reported in the literature for softwoods. ${ }^{48}$ The sodiumhydroxide-extracted samples show a reduced amount of acid-soluble lignin. This suggests that the sodium hydroxide wash further removed lignin degradation products. Hydrolysate analytical data for sugars typical of $P$. radiata show that there is no reduction in the amount of residual hemicellulose (Table 2). This implies that the treatment is relatively selective in only attacking the lignin, leaving the hemicellulose component of the cell wall intact.

The ${ }^{13} \mathrm{C}$ CP/MAS data suggest that most of the lignin has been removed by the oxone oxidation treatments, more so for the alkaline-washed samples, where acetyl groups (methyl carbon at $21 \mathrm{ppm}$ and carbonyl carbon at $173 \mathrm{ppm}$ ) on hemicelluloses have also been removed. The presence of a broad lignin band at $150 \mathrm{ppm}$ also suggests that the structure of the residual lignin is unchanged compared with the control sample. The reduced C- 4 band at $84 \mathrm{ppm}$ and the C-6 band at $63 \mathrm{ppm}$ correspond to non-crystalline cellulose and hemicellulose. The reduced intensities of those bands suggest some dissolution of non-crystalline polysaccharides, while the analogous crystalline cellulose bands (89 and $66 \mathrm{ppm}$ ) resist any dissolution due probably to inaccessibility of reaction solution.

Both analytical methods, ${ }^{13} \mathrm{C}$ NMR and carbohydrate analyses, used on the well-reacted microtomed sections of oxone, or chlorite-treated wood, have produced data that support preferential removal of lignin over hemicelluloses. This contrasts with findings based on analytical data from weathering of $P$. radiata wood strips, ${ }^{3}$ supporting removal of both lignin and hemicelluloses, and to a much lesser extent, cellulose itself. It is known from pulping studies that covalent linkages exist between lignin and polysaccharides in wood. $^{49}$ The relative lack of carbohydrate removal in the treatment of solid wood as a delignified substrate is presumably due to a lack of access of treatment chemicals, through diffusion-controlled processes, which resulted in very little oxidation of carbohydrates in the wood cell walls. 
Practical implications of the work presented here are that controlled surface delignification could be used as an industrial process to produce wooden surfaces compatible for finishing with clear coatings for service in exterior situations. Chemical delignification with peracetic acid may be more suitable for commercialization than accelerated preweathering, mainly because of the time factor, but further development, investment, and refinement are required to produce a market-ready technology. The use of a peracid solid wood treatment technology came from the pulping industry that employs strongly oxidizing and nonchlorine containing agents. In a pulp mill, peracids can be used with oxygen, peroxide, and ozone to meet low levels of chlorinated organic compounds. Nonchlorine delignifying or brightening technologies are increasingly necessary due to environmental concerns. This potentially signifies that if a chemical treatment plant to partially delignify solid wood surfaces was developed on an existing pulping site, the requirements for new equipment or rearranging the existing plant to use peracids would be minimal. This is important due to limitations on both capital and space. ${ }^{50}$

\section{Conclusions}

Both microscopic and analytical techniques used provided evidence that our intended aim of achieving controlled delignification confined to surface layers of panels was met. The partially delignified wooden surfaces, of paler color, obtained in our work, either by peracetic acid or preweathering treatment, will reflect and scatter visible light more effectively and with less absorption of both visible and ultraviolet light due to the reduction in light absorbing lignin functional groups present especially in the top $1500 \mu \mathrm{m}$. This effect, when combined with a lowering of density in this partially delignified region (to a depth of $700 \mu \mathrm{m}$ in latewood and $1500 \mu \mathrm{m}$ in earlywood when peracetic acid treated), appears to suggest that light would penetrate the wooden surface to a greater depth before complete attenuation. However, this needs to be determined. The lower density and less light-absorbing nature of the partially delignified surface zone of $P$. radiata will act to mitigate the photodegradative effects of UV and visible radiation.

Ultrastructural changes occurring during the peracetic acid treatment were complete lignin removal from the cell corner middle lamella regions of cells in the outer layers but with the wood fibers still joined to each other. The secondary wall layers $S_{1}, S_{2}$, and $S_{3}$ also lost their lignin; however, the extent of lignin loss varied with depth, and the secondary wall kept its integrity. These ultrastructural changes can be contrasted with those occurring during photodegradation in the weathering processes of untreated control timber samples where lignin losses from the entire middle lamella resulted in complete cell separation in the outermost layers. $^{32}$

Analytical data have shown preferential lignin removal over that of hemicelluloses during the laboratory oxidative treatment of solid wood sections. The combination of analytical and microscopic techniques used for characterization of the substrate produced for clear coating provided evidence of partial delignification of solid wood surfaces, reflecting a mild environment where preferential lignin loss can occur at the surface, increasing porosity of wood, without destroying the integrity of wood tissues. This is in contrast to more aggressive conditions in pulping situations where substantial amounts of carbohydrates are removed in addition to lignin, and cells are thus prone to delamination.

As a result of reduced lignin concentration of surface layers due to chemical or preweathering treatment, the net impact of solar irradiation on the remaining surface population of lignin molecules may be diminished. Such surfaces may be surface coated with clear coatings. In Part $2^{22}$ of this series, the weathering performance of clear-coated delignified boards on exterior and accelerated exposure is assessed.

Acknowledgments Noel Owen, Department of Chemistry, Brigham Young University, Provo, Utah, is thanked for assistance with infrared microscopy. Anni Ratz is thanked for assistance in producing light microscopy images. The New Zealand Foundation for Research, Science and Technology funded this work.

Open Access This article is distributed under the terms of the Creative Commons Attribution Noncommercial License which permits any noncommercial use, distribution, and reproduction in any medium, provided the original author(s) and source are credited.

\section{References}

1. Derbyshire, H, Miller, ER, "The Photodegradation of Wood During Solar Irradiation." Holz als Roh- und Werkstoff, 39 341-350 (1981)

2. Williams, RS, "Effect of Grafted UV Stabilizers on Wood Surface Erosion and Clear Coating Performance." J. Appl. Polym. Sci., 28 2093-2103 (1983)

3. Evans, PD, Michell, AJ, Schmalzl, KJ, "Studies of the Degradation and Protection of Wood Surfaces." Wood Sci. Technol., 26 151-163 (1992)

4. MacLeod, IT, Scully, AD, Ghiggino, KP, Ritchie, PJA, Paravagna, OM, Leary, B, "Photodegradation at the WoodClearcoat Interface." Wood Sci. Technol., 29 183-189 (1995)

5. Evans, PD, Thay, PD, Schmalzl, KJ, "Degradation of Wood Surfaces During Natural Weathering. Effects on Lignin and Cellulose and on the Adhesion of Acrylic Latex Primers." Wood Sci. Technol., 30 411-422 (1996) 
6. Hill, CAS, Cetin, NS, Quinnery, RF, Derbyshire, H, Ewen, RJ, "An Investigation of the Potential for Chemical Modification and Subsequent Grafting as a Means of Protecting Wood Against Photodegradation." Polym. Degrad. Stab., 72 133-139 (2001)

7. Evans, PD, Owen, NL, Schmid, S, Webster, RD, "Weathering and Photostability of Benzoylated Wood." Polym. Degrad. Stab., 76 291-303 (2002)

8. Xie, Y, Krause, A, Mai, C, Militz, H, Richter, K, Urban, K, Evans, PD, "Weathering of Wood Modified with the $\mathrm{N}$-methylol Compound 1,3-Dimethylol-4,5-Dihydroxyethyleneurea." Polym. Degrad. Stab., 89 189-199 (2005)

9. George, B, Suttie, E, Merlin, A, Deglise, X, "Photodegradation and Photostabilisation of Wood-The State of the Art." Polym. Degrad. Stab., 88 268-274 (2005)

10. Williams, RS, "Weathering of Wood." In: Rowell, RM (ed.) Handbook of Wood Chemistry and Wood Composites. CRC Press, Boca Raton (2005)

11. Schmalzl, KJ, Forsyth, CM, Evans, PD, "Evidence for the Formation of Chromium (III) Diphenoquinone Complexes During Oxidation of Guaiacol and 2,6-Dimethoxyphenol with Chromic Acid." Polym. Degrad. Stab., 82 399-407 (2003)

12. Kiguchi, M, Evans, PD, Ekstedt, J, Williams, RS, Kataoka, Y, "Improvement of the Durability of Clear Coatings by Grafting of UV-Absorbers on to Wood." Surf. Coat. Int. Part B: Coat. Trans., 84 (4) 263-270 (2001)

13. Williams, RS, Knaebe, MT, Sotos, PG, Feist, WC, "Erosion Rates of Wood During Natural Weathering. Part 1. Effects of Grain and Surface Texture." Wood Fiber, 33 (1) 31-42 (2001)

14. Williams, RS, Knaebe, MT, Feist, WC, "Erosion Rates of Wood During Natural Weathering. Part 2. Earlywood and Latewood Erosion Rates." Wood Fiber, 33 (1) $43-49$ (2001)

15. Hon, DN-S, Chang, S-T, "Photoprotection of Wood Surfaces by Wood-Ion Complexes." Wood Fiber Sci., 17 (1) 92-100 (1985)

16. Chang, S-T, Hon, DN-S, Feist, WC, "Photodegradation and Photoprotection of Wood Surfaces." Wood Fiber, 14 (2) 104117 (1982)

17. Schmalzl, KJ, Evans, PD, "Wood Surface Protection with Some Titanium, Zirconium and Manganese Compounds." Polym. Degrad. Stab., 82 409-419 (2003)

18. Grelier, S, Castellan, A, Desrousseaux, S, Nourmamode, A, Podgorski, L, "Attempt to Protect Wood Colour Against UV/Visible Light by Using Antioxidants Bearing Isocyanate Groups and Grafted to the Material with Microwave." Holzforschung, 51 (6) 511-518 (1997)

19. Rowell, RM, "Chemical Modification of Wood." In: Hon, DN-S, Shiraishi, N (eds.) Wood and Cellulosic Chemistry, pp. 703-756. Marcel Dekker, New York (1991)

20. Torr, KM, Dawson, BSW, Ede, RM, Singh, J, "Surface Changes on Acetylation and Exposure to Ultraviolet Radiation of $P$. radiata Using X-ray Photo-electron Spectroscopy." Holzforschung, 50 (5) 449-456 (1996)

21. Kiguchi, M, "Photo-Deterioration of Chemically Modified Wood Surfaces: Acetylated Wood and Alkylated Wood." Jpn. Agric. Res. Quart., 31 (2) 147-154 (1997)

22. Dawson BSW, Singh AP, Kroese HW, Schwitzer MA, Gallagher S, Riddiough SJ, Wu S, "Enhancing Exterior Performance of Clear Coatings Through Photostabilisation of Wooden Surfaces. Part 2. Coating and Weathering Performance," J. Coat. Technol. Res., 5 (2) (2008)

23. Vogel, AI, A Text-book of Quantitative Inorganic Analysis (3rd ed.). Longmans, London (1961)
24. Nakano, J, Meshitsuka, G, "The Detection of Lignin." In: Dence, CW, Lin, SY (eds.) Methods in Lignin Chemistry, pp. 23-32. Springer-Verlag, Berlin (1992)

25. Australian Standard/New Zealand Standard 1301.426s:1994. Determination of Thickness and Apparent Bulk Density or Apparent Sheet Density (1994)

26. Spurr, AR, "A Low Viscosity Embedding Medium for Electron Microscopy." J. Ultrastruct. Res., 26 31-43 (1969)

27. Tappi Method, T 222 OM-88, "Acid Insoluble Lignin in Wood and Pulp" (1988)

28. Appita Standard P11s-78. Klason Lignin in Wood and Pulp (1978)

29. Johnson, DB, Moore, WE, Zank, LC, "The Spectrophotometric Determination of Lignin in Small Wood Samples." Tappi, 44 (11) 793-798 (1961)

30. Marton, J, "Determination of Lignin in Small Pulp and Paper Samples Using the Acetyl Bromide Method." Tappi, 50 (7) 335-337 (1967)

31. Fukushima, RS, Hatfield, RD, "Extraction and Isolation of Lignin for Utilization as a Standard to Determine Lignin Concentration Using the Acetyl Bromide Spectrophotometric Method." J. Agric. Food Chem., 49 (7) 3133-3139 (2001)

32. Tappi Useful Method, UM-250. "Acid Soluble Lignin in Wood and Pulp" (1985)

33. Pettersen, RC, Schwandt, VH, "Wood Sugar Analysis by Anion Chromatography." J. Wood Chem. Technol., 11 (4) 495-501 (1991)

34. Singh, AP, Dawson, BSW, "The Mechanism of Failure of Clear Coated Wooden Boards as Revealed by Microscopy." IAWA J., 24 (1) 1-11 (2003)

35. Iiyama, K, Wallis, AFA, "An Improved Acetyl Bromide Procedure for Determining Lignin in Woods and Wood Pulps." Wood Sci. Technol., 22 271-280 (1988)

36. Leary, GJ, Newman, RH, Morgan, KR, "A Carbon-13 Nuclear Magnetic Resonance Study of Chemical Processes Involved in the Isolation of Klason Lignin." Holzforschung, 40 (5) 267-272 (1986)

37. Leary, GJ, Morgan, KR, Newman, RH, "Solid State Carbon13 Nuclear Magnetic Resonance Study of $P$. radiata Wood." Appita, 40 (3) 181-184 (1987)

38. Schniewind, AP, "Mechanism of Check Formation." Forest Prod. J., 13 (11) 475-480 (1963)

39. Christy, AG, Senden, TJ, Evans, PD, "Automated Measurement of Checks at Wood Surfaces." Measurement, 37 109_ 118 (2005)

40. Evans, R, Downes, G, Menz, D, Stringer, S, "Rapid Measurement of the Variation in Tracheid Transverse Dimensions in a P. radiata Tree." Appita, 93 113-119 (1993)

41. Evans, R, "Rapid Measurement of the Transverse Dimensions of Tracheids in Radial Wood Sections from P. radiata." Holzforschung, 48 (2) 168-172 (1994)

42. Evans, R, Downes, G, "Recent Developments in Automated Wood Quality Assessment," Eucalypt Plantations: Improving Fibre Yield and Quality. In: Potts, BM, Barrahlo, NMG, Reid, JB, Cromer, RN, Tibbits, WN, and Raymond, CA (eds.) Proceedings, CRC-IUFRO Conf., pp. 101-105 (1995)

43. Hon, DN-S, "Photochemistry of Wood." In: Hon, DN-S, Shiraishi, N (eds.) Wood and Cellulosic Chemistry, pp. 525555. Marcel Dekker, New York (1991)

44. Kataoka, Y, Kiguchi, M, Evans, PD, "Photodegradation Depth Profile and Penetration of Light in Japanese Cedar Earlywood (Cryptomeria japonica D. Don) Exposed to Artificial Solar Radiation." Surf. Coat. Int. Part B: Coat. Trans., 87 (3) 187-193 (2004) 
45. Siddiqui, KM, "Relationship Between Cell Wall Morphology and Chemical Composition of Earlywood and Latewood in Two Coniferous Species." Pak. J. Forest., 26 (1) 21-34 (1976)

46. Kataoka, Y, Kiguchi, M, "Depth Profiling of Photo-induced Degradation in Wood by FTIR Microspectroscopy." J. Wood Sci., 47 325-327 (2001)

47. Kataoka, Y, Kiguchi, M, Fujiwara, T, Evans, PD, "The Effects of Within-Species and Between-Species Variation in Wood Density on the Photodegradation Depth Profiles of Sugi (Cryptomeria japonica) and Hinoki (Chamaecyparis obtusa)." J. Wood Sci., 51 531-536 (2005)
48. Uprichard, JM, "Chemistry of Wood and Bark." In: Kininmonth, JA, Whitehouse, LJ (eds.) Properties and Uses of New Zealand Radiata Pine, pp. 4.1-4.45. New Zealand Ministry of Forestry, Forest Research Institute, Rotorua (1991)

49. Sjostrom, E, Wood Chemistry, Fundamentals and Applications. Academic Press Inc., Orlando (1981)

50. Amini, B, Webster, J, "On-site Peracids: Tools for Bleaching Strategies to Meet the Cluster Rule and Considerations on Selecting Among Them." Tappi J., 78 (10) 121-133 (1995) 